\title{
Oral parafunctions, personality traits, anxiety and their association with signs and symptoms of temporomandibular disorders in the adolescents
}

\author{
Saadet Sağlam Atsü${ }^{1}$, Sibel Güner ${ }^{2}$, Nilgün Palulu ${ }^{3}$ Ali Can Bulut ${ }^{1}$, Işın Kürkçüoğlu ${ }^{4}$
}

1. Department of Prosthodontics, Faculty of Dentistry, University of Kur1kkale, Kurıkkale, Turkey.

2. Department of Orofacial Pain, Ankara Center of Oral and Dental Health, Department of Orofacial Pain, Ankara, Turkey.

3. Department of Physical Rehabilitation, Dr. Behçet Uz Children Hospital, Department of Physical Rehabilitation, İzmir, Turkey.

4. Department of Prosthodontics, Faculty of Dentistry, University of Suleyman Demirel, Isparta, Turkey.

\begin{abstract}
:
Objectives: To investigate the association between oral parafunctions, personality traits, anxiety and signs and symptoms of temporomandibular disorders in the adolescents.

Methods: Two hundred and seventy adolescents were examined clinically for the signs and symptoms of temporomandibular disorders. Participants completed questionnaires about demographic variables, medical history, symptoms of temporomandibular disorders, parafunctional oral habits, Minnesota Multibasic Personality Inventory, and Spielberger State-Trait Anxiety Inventory.

Results: Logistic regression analyses revealed that bruxism was associated with joint tenderness (Odds ratio $(\mathrm{OR})=6.38, \mathrm{p}<$ $0.01)$, joint noises $(\mathrm{OR}=6.02, \mathrm{p}<0.01)$ and masticatory muscle tenderness $(\mathrm{OR}=4.19, \mathrm{p}<0.05)$ to palpation. State anxiety showed increased risk of joint tenderness $(\mathrm{OR}=2.47, \mathrm{p}<0.05)$ and muscle tenderness $(\mathrm{OR}=3.25, \mathrm{p}<0.05)$ to palpation.

Conclusion: Within the limitations of this study, it was concluded that oral parafunctions, especially bruxism, state anxiety, depression and hysteria were associated with signs and symptoms of temporomandibular disorders in adolescents.

Keywords: Oral parafunctions, personality traits, signs and symptoms of temporomandibular disorders, adolescents.

DOI: https://dx.doi.org/10.4314/ahs.v19i1.57

Cite as: Atsü SS, Güner S, Palulu N, Bulut AC, I K. Oralparafunctions, personality traits, anxiety and their association with signs and symptoms of temporomandibular disorders in the adolescents. Afri Health Sci. 2019;19(1). 1801-1810. https:// dx.doi. org/10.4314/ abs. v19i1.57
\end{abstract}

\section{Introduction}

It is generally accepted that the temporomandibular disorders (TMDs) are of multifactorial etiology in nature. Oral parafunctions, malocclusion, emotional status, and

\section{Correspondece author:}

Saadet Sağlam Atsü, Department of Prosthodontics, University of Kurıkkale, Faculty of Dentistry, Yenişehir Mahallesi Çelebi Sokak No:1

Yahşihan/ Kirıkkale

Tel: 00903182244927

Email: saadetats@yahoo.com trauma are the known contributing factors ${ }^{1-3}$. Parafunctional habits are frequently observed in the general population and can lead to damage to dentition, masticatory system and/or joints when they exceed the individual's physiological tolerance and the structural tolerance of masticatory system ${ }^{3}$. Prevalence of parafunctions and the relationship between parafunctions and TMDs signs and symptoms were reported by several authors in children, adolescents and adults ${ }^{1-9}$. Several studies reported a relationship between oral parafunctions and tenderness in masticatory muscles and temporomandibular joints $(\mathrm{TMJ})^{1,2,4-6,8-12}$.

Another crucial area for TMDs etiology is the psychological factors however their role in the development of

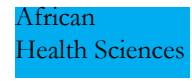

(C) 2019 Atsü et al. Licensee African Health Sciences. This is an Open Access article distributed under the terms of the Creative commons Attribution License (https://creativecommons.org/licenses/BY/4.0), which permits unrestricted use, distribution, and reproduction in any medium, provided the original work is properly cited. 
TMDs disorders still remains as a controversial issue ${ }^{13-16}$. Personality characteristics of patients with TMDs, especially with myofascial pain (MFP), were shown to have higher scores on hypochondriasis, hysteria, and/or depression within the normal range $e^{15,17-20}$. Some authors reported that patients with masticatory muscle pain were more inclined to have stress and depression ${ }^{14,15,19,20}$. Stress and anxiety are the most effective psychological factors on TMDs because stress can induce muscle hyperactivity, which in turn causes symptoms of TMDs ${ }^{16}$.

Several epidemiological studies have shown that the signs and symptoms of TMDs are common among adolescents and furthermore parafunctional oral habits are often seen in this age group ${ }^{1,2}$. The role of parafunctional activity and mental state as a predisposing factor of TMDs is still contradictory and little is known about their association with signs and symptoms of TMDs in adolescents. Therefore, the aim of the present study was to investigate the association between oral parafunctions, personality traits, anxiety and signs and symptoms of TMDs in the adolescents.

\section{Materials and methods}

This study was approved by the Ethics Review Board of Kirikkale University Faculty of Dentistry. A total of 282 adolescents were consecutively selected from a high school in Ankara, Turkey. However, 12 subjects who undergone orthodontic treatment, who had a toothache, dentofacial injury and any infection and systemic disease that could affect temporomandibular disorders were excluded from the study. The remaining 270 participants were composed of 209 females and 61 males ranged in age from 15 to 18 years with a mean age of 16.2 \pm 1.0 . The adolescent participants and their parents were informed about the purpose of this study and all participants gave their consent. All participants completed self-administered questionnaires consisting of questions about demographic variables, medical history, parafunctional oral habits, TMDs symptoms, and Minnesota Multibasic Personality Inventory (MMPI) and the Spielberger State and Trait Anxiety Inventory (STAI), under the guidance of a dentist and a psychologist. Clinical examination of the masticatory system was also carried out after the completion of questionnaires.

Questionnaire: According to American Academy of Orofacial Pain Guidelines ${ }^{21}$, the subjects were asked about TMDs symptoms (yes or no questions) including, headache, pain in the face, sounds in TMJ, difficulty in mouth opening and closing, mastication, and fatigue in muscles. To get information on oral parafunctions, following questions that required dichotomous answer (yes/ no) were asked to participants and their parents: "Are you aware of bruxism?" or "Has anyone told you that you grind your teeth?", "Do you bite tongue and/or lip?", "Do you bite fingernails?", "Do you bite hard objects?" and "Do you lean on your arms for prolonged periods?". As it is difficult to indicate sleep bruxism, following questions were also asked to the participants: "Is there any knowledge of night-time bruxing or grinding reported by a family member?", "Is there pain or stiffness in the jaw area upon awaking in the morning?", and "Is there joint click at the first mouth opening in the morning?"2. The information on TMD symptoms and oral parafunctions over the previous 6 mounts was collected ${ }^{2,4}$. In addition, two psychometric tests, Minnesota Multibasic Personality Inventory (MMPI) 22 (Turkish abbreviated version-with normative data calibrated with a Turkish reference population) and Spielberger State and Trait Anxiety Inventory (STAI) ${ }^{23}$ were administered. The participants were also asked questions about parental socioeconomic status (low, middle, high) and education level. Socioeconomic status of the parents was rated based on parental occupation (low: unskilled and skilled workers, middle: civil servants, teachers, etc., high: doctors, engineer, lawyers, etc. $)^{24}$.

Clinical examination: Clinical examinations were performed by an examiner from the Centre of Oral and Dental Health, Department of Orofacial Pain, Ankara Hospital (Ankara, Turkey) who was not informed about the questionnaire results. Clinical examination of masticatory system was carried out according to the American Academy of Orofacial Pain Guidelines ${ }^{21}$ :

TMJ sounds: Presence of joint clicking/crepitation in opening, closing or lateral movements of mandible was recorded.

TMJ pain: TMJ pain was determined by palpation of lateral and posterior aspects of TMJ in rest and/or in function. Visual analog scale (VAS) (a 10-centimeter (cm) linear horizontal graded scale) was used to assess the subjective intensity of pain. 
Muscle tenderness: The following muscle sites were palpated bilaterally: the anterior, middle and posterior portions of the temporal muscle, superficial and deep portions of the masseter muscle and the medial pterygoid muscle. VAS was used to assess the intensity of pain.

Range of mandibular motion: The vertical range of motion of the mandibula, maximum unassisted opening, maximum assisted opening and the extent of mandibular excursive movements were measured by a millimeter ruler (Stainless steel two sided ruler, Miller Dial Corp, El Monte, California) (less than 40, 50 and $7 \mathrm{~mm}$ are considered the limits for maximum unassisted and maximum assisted opening and the extent of mandibular excursive movements, respectively) ${ }^{8,21}$. Maximum unassisted opening was assessed by asking the patient to open the mouth as widely as possible. At this point, the patient was stopped and the distance between the maxillary and mandibular incisors was measured by a millimeter ruler. Assisted opening was evaluated by asking the patientto open the mouth as widely as possible and then the clinician applied gentle force to jaws. Pain during the motions was assessed with VAS. Deviation in the coronal plane was recorded.

After the clinical examination, subjects were informed about necessary oral hygiene training, required dental and
TMD treatments including medications, self-care instructions, physical therapy, and intraoral appliance therapy. Binary logistic regression analysis was used to identify the most important oral parafunctional habits, MMPI and STAI scales (independent variables) affecting each of the signs and symptoms of TMDs (dependent variables). As a predictor, an odds ratio was considered meaningful for clinical use. The chi-square test was used to compare non-numerical and categorical variables such as gender, educational level and parental socio-economic status. Independent t-tests were used to determine the mean differences in the level of pain (VAS). The results were evaluated at significance level of $\mathrm{p}<0.05$. All the analyses were performed by using the Minitab 13.0 (Minitab Statistical Software version 13.00, 2000).

\section{Results}

The distribution of the socio-demographic characteristic of the groups is shown in Table 1. In terms of demographic variables, no statistically significant differences were observed between the subjects exhibiting or not exhibiting signs or symptoms of TMDs except for gender. The chi-square test revealed that the ratio of females was significantly higher among the adolescent subjects exhibiting signs or symptoms of TMDs than the adolescents without any signs and symptoms of TMDs ( $p<0.01)$.

Table 1. Socio-demographic characteristics of the subjects.

\begin{tabular}{llll}
\hline Variable & $\begin{array}{l}\text { Subjects exhibiting signs } \\
\text { or symptoms of TMDs }\end{array}$ & $\begin{array}{l}\text { Subjects not exhibiting } \\
\text { signs or symptoms of TMDs }\end{array}$ & $p<$ values \\
Gender (Female/male) & $129 / 32$ & $80 / 29$ & $p<0.01$ \\
$\quad(\%)$ & $47.8 / 11.8$ & $29.6 / 10.8$ & NS \\
Age (Mean and SD) & $16.2 \pm 1.0$ & $16.1 \pm 1.1$ & NS \\
Parental socioeconomic status & & & \\
$\quad(\%)$ & & & \\
Low & 23.5 & 20.5 & \\
Medium & 70.7 & 74.4 & \\
High & 5.8 & 5.1 & \\
\hline
\end{tabular}

$\mathrm{NS}=$ not significant 
The prevalences of TMDs symptoms reported as TMJ noise, facial pain, difficulty in mouth opening and in mouth closing, in chewing and tired jaws in subjects were 42.9, 22.9, 18.3, 9.5, 26.7, and 39.0\%, respectively. The prevalences of TMDs signs as TMJ tenderness, TMJ noise, muscle tenderness and limited mandibular motion in subjects were $34.4,44.8,36.7$, and $14.3 \%$, respectively. Prevalence of oral parafunctions in subjects is shown Table 2.

Table 2. Prevalence of oral parafunctions in the subjects

\begin{tabular}{lllll}
\hline Variables & $\begin{array}{l}\text { Subjects exhibiting signs } \\
\text { symptoms of TMDs }\end{array}$ & $\begin{array}{l}\text { Subjects not exhibiting signs } \\
\text { or symptoms of TMDs }\end{array}$ \\
& 41.0 & $(69.6 \%)$ & $(40.4 \%)(\mathrm{N}=109)$ \\
Bruxism & 21.7 & $(35)$ & 17.4 & $(19)$ \\
Nail biting & 12.4 & $(20)$ & 6.4 & $(7)$ \\
Tongue biting & 28.6 & $(46)$ & 2.7 & $(3)$ \\
Lip biting & 13.0 & $(21)$ & 13.8 & $(15)$ \\
Holding an objects & 43.5 & $(70)$ & 2.7 & $(3)$ \\
Leaning on arm & & & 29.4 & $(32)$ \\
\hline
\end{tabular}

Values in the brackets show the number of subject in the groups

The most frequent oral parafunctional habit was leaning on arms for prolonged periods $(43.5 \%)$, followed by bruxism (41\%), lip biting (28.6\%), nail biting (21.7\%), holding an object in the mouth (13\%) and tongue biting $(12.4 \%)$ in the subject with TMDs. The prevalence of oral parafunctions in all subjects were found as following: Leaning on arms (37.8\%), bruxism (31.5\%), lip biting (22.6\%), nail biting (15.5\%), holding an object in the mouth $(8.9 \%)$ and tongue biting $(8.5 \%)$. Pain intensity (VAS) scores are shown in Table 3. 
Table 3. Pain intensity of subjects exhibiting and not exhibiting signs or symptoms of TMDs

\begin{tabular}{|c|c|c|c|}
\hline $\begin{array}{l}\text { Pain intensity } \\
(\mathrm{VAS}, \text { mean } \pm \mathrm{SD})\end{array}$ & $\begin{array}{l}\text { Subjects exhibiting signs } \\
\text { or symptoms of TMDs }\end{array}$ & $\begin{array}{l}\text { Subjects not exhibiting signs } \\
\text { or symptoms of TMDs }\end{array}$ & $p$ values \\
\hline TMJ & $4.02 \pm 1.20$ & $2.14 \pm 0.45$ & $p<0.05$ \\
\hline \multicolumn{4}{|l|}{ Masticatory muscles } \\
\hline Masseter & $4.70 \pm 1.69$ & $1.23 \pm 0.50$ & $p<0.001$ \\
\hline Temporalis & $5.02 \pm 2.80$ & $2.55 \pm 1.08$ & $p<0.001$ \\
\hline Medial pterygoid & $3.08 \pm 2.20$ & $1.47 \pm 0.34$ & $p<0.01$ \\
\hline \multicolumn{4}{|l|}{ Mandibular motion } \\
\hline $\begin{array}{l}\text { Maximum unassisted } \\
\text { opening }\end{array}$ & $4.91 \pm 2.62$ & $2.10 \pm 1.50$ & $p<0.001$ \\
\hline Assisted opening & $5.55 \pm 1.71$ & $3.10 \pm 1.31$ & $p<0.001$ \\
\hline $\begin{array}{l}\text { Mandibular excursive } \\
\text { movement }\end{array}$ & $4.18 \pm 2.91$ & $2.50 \pm 1.33$ & $p<0.001$ \\
\hline
\end{tabular}

The independent t-tests showed statistically significant deviations of MMPI and STAI values of subjects with difference between the groups. The means and standard and without TMDs are shown in Figure 1 and 2.

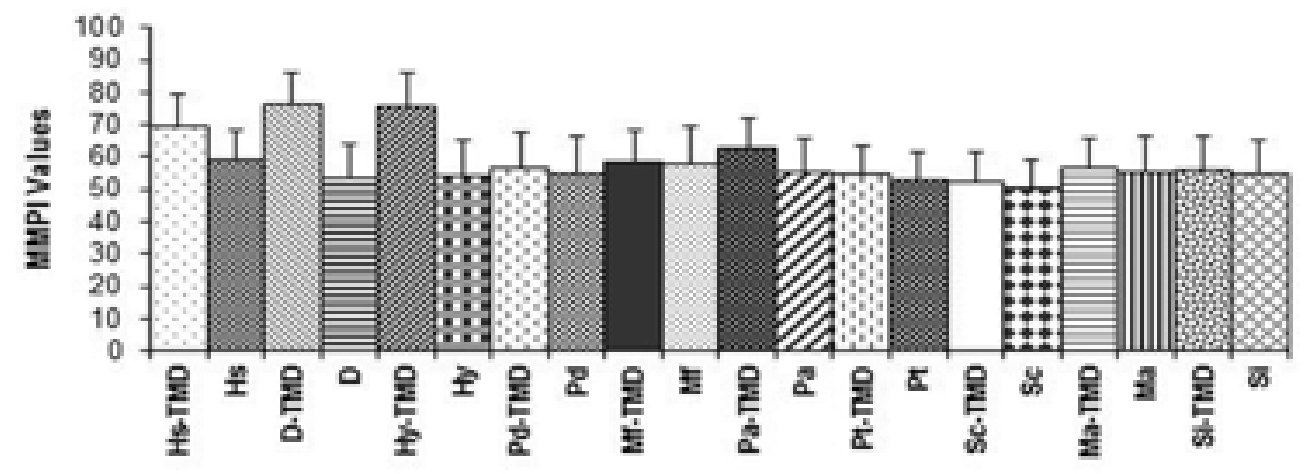

Figure 1. Mean $( \pm S D)$ values of MMPI for subjects exhibiting and not exhibiting signs or symptoms of TMDs. Hs: Hypochondriasis, D: Depression, Hy: Hysteria, Pd: Psychopathic deviation, Mf: Masculinity-femininity,

Pa: Paranoia, Pt: Psychastenia, Sc: Schizophrenia, Ma: Mania, Si: Social introversion

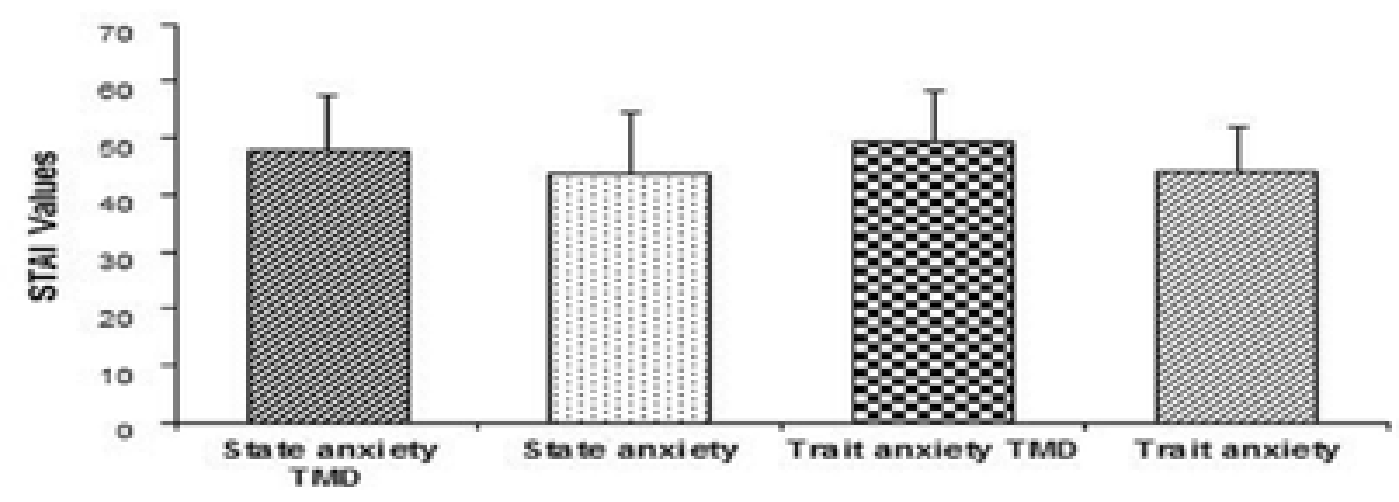

Figure 2. Mean ( \pm SD) values of STAl for subjects exhibiting and not exhibiting signs or symptoms of TMDs 
Table 4 shows the significant habits, MMPI and STAI scales for each self-reported symptom of TMDs revealed by the logistic regression analysis, which have statistically significant $\mathrm{p}$ values and positive coefficients. The analysis revealed that bruxism was associated with joint noises $(\mathrm{OR}=2.33, \mathrm{p}<0.05)$, headache $(\mathrm{OR}=2.89, \mathrm{p}<0.05)$, facial pain $(\mathrm{OR}=2.44, \mathrm{p}<0.05)$, difficulty in opening $(\mathrm{OR}=4.94, \mathrm{p}<0.05)$, closing $(\mathrm{OR}=3.58, \mathrm{p}<0.05)$, chewing $(\mathrm{OR}=2.69, \mathrm{p}<0.05)$, and tired jaws $(\mathrm{OR}=2.75, \mathrm{p}<$
0.05). Nail biting and lip biting related with joint noises $(\mathrm{OR}=3.24, \mathrm{OR}=3.08, \mathrm{p}<0.05)$ and tired jaws $(\mathrm{OR}=2.52$, $\mathrm{OR}=3.21, \mathrm{p}<0.05)$, respectively. Subjects with higher scores of hysteria were 4.3 times more prone to feel facial pain and had a 6 times higher tendency to have tired jaws. Subjects with high scores on depression were 3.6 times more prone to have facial pain, whereas subjects with high scores on state anxiety were also 2.6 times more prone to have facial pain and 4 times more prone to have tired jaws.

Table 4. Significant parafunctions, personality traits and anxiety for each self-reported TMDs symptom

\begin{tabular}{|c|c|c|c|c|c|c|c|}
\hline Predictor & TMJ noise & Headache & Facial pain & $\begin{array}{l}\text { Difficultyin } \\
\text { opening }\end{array}$ & $\begin{array}{l}\text { Difficulty } \\
\text { in closing }\end{array}$ & $\begin{array}{l}\text { Difficulty } \\
\text { chewing }\end{array}$ & $\begin{array}{ll}\text { in } & \begin{array}{l}\text { Tired } \\
\text { jaw }\end{array}\end{array}$ \\
\hline \multicolumn{8}{|l|}{ Bruxism } \\
\hline OR & $2.33 *$ & $2.89 *$ & $2.44 *$ & $4.94 *$ & $3.58 *$ & $2.69^{*}$ & $2.75^{*}$ \\
\hline $95 \%$ CI & $2.10-3.30$ & $2.30-13.91$ & $2.10-11.94$ & $2.59-41.3$ & $2.42-37.50$ & $2.10-11.25$ & $2.01-10.35$ \\
\hline \multicolumn{8}{|l|}{ Nail biting } \\
\hline OR & $3.24 *$ & & & & & & $2.52 *$ \\
\hline $95 \% \mathrm{CI}$ & $2.66-15.8$ & & & & & & $2.27-16$ \\
\hline \multicolumn{8}{|l|}{ Lip biting } \\
\hline OR & $3.08 *$ & & $3.13 *$ & $2.29 *$ & & & $3.21 *$ \\
\hline $95 \%$ CI & $2.97-12.21$ & & $2.95-19.36$ & $2.02-11.63$ & & & $2.05-18.39$ \\
\hline \multicolumn{8}{|l|}{ Depression } \\
\hline OR & & & $3.66^{*}$ & & & & \\
\hline $95 \% \mathrm{CI}$ & & & $2.68-19.74$ & & & & \\
\hline \multicolumn{8}{|l|}{ Hysteria } \\
\hline OR & & & $4.35^{*}$ & & & & $5.91 *$ \\
\hline $95 \%$ CI & & & $3.53-35.97$ & & & & $3.13-31.01$ \\
\hline \multicolumn{8}{|l|}{ State } \\
\hline anxiety & $2.62 *$ & & & & & & $4.07 *$ \\
\hline OR & $2.88-7.78$ & & & & & & $2.98-16.87$ \\
\hline $95 \% \mathrm{CI}$ & & & & & & & \\
\hline
\end{tabular}

$* \mathrm{p}<0.05$, OR: Odds Ratio

Table 5 shows the significant habits, MMPI and STAI scales for each sign of TMDs revealed by the logistic regression analysis, which have statistically significant $\mathrm{p}$ values and positive coefficients. The analysis revealed that bruxism was associated with joint tenderness $(\mathrm{OR}=6.38$, $\mathrm{p}<0.01)$, joint noises $(\mathrm{OR}=6.02, \mathrm{p}<0.01)$ and muscle tenderness $(\mathrm{OR}=4.19, \mathrm{p}<0.05)$. Nail biting resulted in approximately 6 (5.86) times higher tendency to develop muscle tenderness. The logistic regression analysis showed that depression $(\mathrm{OR}=5.88, \mathrm{p}<0.01)$ and hysteria $(\mathrm{OR}=2.94, \mathrm{p}<0.05)$ had a significant effect on muscle tenderness. State anxiety was related with joint tenderness $(\mathrm{OR}=2.47, \mathrm{p}<0.05)$ and muscle tenderness $(\mathrm{OR}=3.25$, $\mathrm{p}<0.05)$. 
Table 5. Significant parafunctions, personality traits and anxiety for each TMDs sign

\begin{tabular}{|c|c|c|c|c|}
\hline $\begin{array}{l}\text { Predictor } \\
\text { Bruxism }\end{array}$ & TMJ tenderness & TMJ noise & Muscle tenderness & Mandibular motion \\
\hline OR & $6.38 * *$ & $6.02 * *$ & $4.19 *$ & $2.52 *$ \\
\hline $95 \% \mathrm{CI}$ & $2.79-22.69$ & $2.65-22$ & $2.26-13.98$ & $2.11-8.35$ \\
\hline \multicolumn{5}{|c|}{ Nail biting } \\
\hline OR & $3.23 *$ & & $5.86^{*}$ & \\
\hline $95 \% \mathrm{CI}$ & $2.10-8.58$ & & $3.79-33.88$ & \\
\hline \multicolumn{5}{|c|}{ Lip biting } \\
\hline OR & $3.11 *$ & & $2.23 *$ & \\
\hline $95 \% \mathrm{Cl}$ & $2.18-5.24$ & & $2.02-4.49$ & \\
\hline \multicolumn{5}{|c|}{ Depression } \\
\hline OR & & & $5.88 * *$ & \\
\hline $95 \% \mathrm{CI}$ & & & $3.51-22.87$ & \\
\hline \multicolumn{5}{|l|}{ Hysteria } \\
\hline OR & & & $2.94 *$ & \\
\hline $95 \% \mathrm{CI}$ & & & $2.71-12.15$ & \\
\hline \multicolumn{5}{|c|}{ State anxiety } \\
\hline OR & $2.47 *$ & & $3.25 *$ & \\
\hline $95 \% \mathrm{CI}$ & $2.10-7.56$ & & $2.29-10.60$ & \\
\hline
\end{tabular}

${ }^{*} p<0.05, * * p<0.01$

Mean ( $\pm S D$ ) values of MMPI for subjects exhibiting and not exhibiting signs or symptoms of TMDs. Hs: Hypochondriasis, D: Depression, Hy:Hysteria, Pd: Psychopathic deviation, Mf: Masculinity-femininity,

Pa:Paranoia, Pt:Psychastenia, Sc: Schizophrenia, Ma:Mania, Si:Social introversion

\section{Discussion}

Parafunctional oral habits have been considered as major causes of TMDs symptoms related with masticatory muscles ${ }^{1-9,11,13,22,25}$. Bruxism has generally been characterized as awake and sleep tooth clenching or grinding in the literature. It is underestimated because this habit is usually performed subconsciously, and most people are unaware of its presence ${ }^{3}$. In the present study, we did not differentiate awake and sleep bruxism like Okeson et al. ${ }^{21}$ and also tooth clenching and grinding because the possibility to make this distinction correctly is very difficult. Previous studies have suggested various techniques to record bruxism. One technique includes the evaluation of the dental attrition, either through visual observations in the mouth or through occlusal appliance or on study casts $^{26}$. However, it is very difficult to determine if it is a consequence of parafunctional or functional habits. Furthermore, dental wear can occur as the result of many factors. Masticatory muscle activity can be measured to assess bruxism using the EMG technique in a sleep laboratory or in patient's own house ${ }^{27}$. Although it is the best way to identify bruxism, such an experimental setup is difficult, expensive and time-consuming. In this study, we used interview and questionnaire methods together with clinical examination, which are the most reported techniques in the literature, to identify bruxism ${ }^{1-8,19,20,24}$. It is well known that bruxism is frequently associated with signs and symptoms of TMDs including muscle and joint sensitivity, joint sounds, chewing and opening problem as reported by several authors ${ }^{2,4,7-10,13,24,28,29}$. Allen et al. ${ }^{11}$ reported that bruxism was significantly associated with symptoms of pain and discomfort in TMJ region. Rugh and Harlan ${ }^{27}$ and Tommaso et al. ${ }^{25}$ reviewed the effects of sleep bruxism on TMDs and surmised that this habit could cause considerable damage to every element of the masticatory system. They were also able to correlate bruxism with muscular headache. Similar results were obtained in the present study. Logistic regression analysis revealed that bruxism was associated with joint tenderness $(\mathrm{OR}=6.38)$, joint noises $(\mathrm{OR}=6.02)$, muscle tenderness $(\mathrm{OR}=4.19)$ to palpation, limited mandibular motion $(\mathrm{OR}=2.52)$ and reported TMJ noise, facial pain, difficul- 
ty in closing, opening and chewing, headache and tired jaws among the adolescent participating in this study. The association between bruxism and limited mandibular motion can be explained by tenderness of the muscles, which was enough to create significant differences in limiting the mandibular motion. The recent studies showed that TMDs pain was correlated with bruxism among adolescents (OR: 1.80 and 2.02) 24,28,29. In this study, a similar association was found between bruxism and facial pain (OR: 2.44).

The prevalence of bruxism for the adolescence subjects in this study was $31.5 \%$, which was slightly lower than the results of Gavish et al. ${ }^{1}$ reporting a prevalence of $44.3 \%$. Our result was in agreement with the findings of Gilheaney et al. ${ }^{5}$ and Vanderas and Papagiannoulis ${ }^{6}$ stating bruxism rates of $34.7 \%$ and $31 \%$ respectively. Some other studies ${ }^{24}$, on the contrary, found lower prevalence values $(8-12 \%)$ in teenagers and adults and showed that the prevalence reduced with age.

Nail biting and holding objects in the mouth are other oral parafunctions observed frequently in children and adolescents ${ }^{2,5,7,12}$. Some oral parafunctions such as thumb sucking may be abandoned gradually during childhood, or may be continued like nail biting, or holding an object in the mouth such as pencil, smoking etc. Winocur et $\mathrm{al}^{2}$ found that biting hard objects and nail biting were associated with tired jaws in adolescent girls. A positive association was observed between nail biting and TMJ sounds, pain in TMJ and masticatory muscles ${ }^{5,712}$. However, Gavish et al. ${ }^{1}$ did not find any association between biting objects and signs and symptoms of TMDs. In the present study, results showed that nail biting was related with muscle tenderness to palpation $(\mathrm{OR}=5.86)$ and reported TMJ noise $(\mathrm{OR}=3.24)$. The prevalence of nail biting in this study was $21.7 \%$, showing no meaningful differences from the findings of previous studies ${ }^{1,7,8}$.

A possible association between continuous arm leaning and biting oral tissues such as lip and tongue biting and TMDs signs and symptoms were also investigated in the present study. In contrast to the findings of Gavish et al. ${ }^{1}$ reporting a positive correlation between leaning on the arm and TMDs signs and symptoms, the present study showed that leaning on the arm had not been a significant risk for the masticatory system. In the present study the prevalence of arm leaning was $43.5 \%$, which was close to the result (44.8\%) of Miyake et $\mathrm{al}^{4}{ }^{4}$ and was higher than the result (29.3\%) reported by Gavish et al. ${ }^{1}$. In this study, subjects with lip biting had a masticatory muscle pain and TMJ tenderness to palpation, reported TMJ noise, facial pain, difficulty in mouth opening and tired jaws compared to the subjects who did not do lip biting. This finding was in line with the results of previous studies showing that biting oral tissues was associated with tired jaws, muscle tenderness, and restricted opening of the mouth ${ }^{1,2,6,7}$. The prevalence of the subjects exhibiting signs or symptoms of TMDs in the studied adolescents population was $59.6 \%$. The results of the present study are consistent with those of Wieckiewicz et al. ${ }^{8}$, who reported that the prevalence of TMDs in a Polish student group (mean age 22 years) is $54 \%$.

The effects of the nail and lip biting on the signs and symptoms of TMDs may be explained with the hyperactivity of the lateral pterygoid muscle. The lateral pterygoid muscle consists of 2 parts (superior and an inferior head) and is active on opening, protrusion and contralateral jaw movements, closing, and ipsilateral jaw movements $^{30}$. Therefore, the lateral pterygoid muscle presumably plays an important role in parafunctional excursive jaw movements.

Development of TMDs may be affected by gender differences. Adolescent females exhibit more temporomandibular symptoms and more clinical signs compared to males $^{31}$. Studies on adult population and students showed that $43-65 \%$ of women and $35-38 \%$ of men had TMDs ${ }^{8}$. In the present study, TMDs signs and symptoms were more frequent in adolescent female group (47.8\%) participating in this study. These results may be explained by the biological differences, the hormone levels and higher pain sensitivity in women.

In this study, the signs and symptoms of TMDs were evaluated according to the American Academy of Orofacial Pain (AAOP) Guidelines. Although the research diagnostic criteria for TMDs (RDC/TMD) has been used in many studies of TMDs, AAOP questions also showed both good reliability and validity for the screening of TMD among adolescents, according to RDC/TMD ${ }^{32}$.

It is largely believed that psychological factors are an important component in the etiology and maintenance of TMDs ${ }^{3,8,14-16}$. Several researchers have shown that patient's personality characteristics which reflect our be- 
havior and responses to stress and anxiety are the significant psychological factors on TMDs ${ }^{14-16}$. Higher levels in hypochondriasis, hysteria, depression and/or anxiety in TMDs patients especially in myofascial pain patients, in which the associated pain of muscular origin rather than joint disease, were reported by the authors ${ }^{8,15,17-20}$. Several studies have also focused on anxiety in the patients with TMDs ${ }^{14,16,19,20}$. It is thought that stress can induce muscle hyperactivity or spasm, which in turn causes symptoms of $\mathrm{TMDs}^{16}$. McCreary et al. ${ }^{14}$ reported that some TMDs patients have more anxiety experience than healthy control groups. Velly et al. ${ }^{19}$ reported that higher scores of anxiety and depression were associated with myofascial pain. Effects of personality characteristics and anxiety on signs and symptoms of TMDs were evaluated in the present study. The results confirmed that TMDs signs and symptoms related with pain showed an association with hysteria, depression and state anxiety. People with high scores on hysteria developed physical symptoms against stress and they had generally headache, chest pain, fatigue and anxiety attacks ${ }^{22}$. These emotional difficulties may lead to the excess muscle tension and may promote parafunctional oral habits. It is also recognized that psychological factors may be involved in the pain perception process $^{33}$. State anxiety associated with muscle and TMJ tenderness, and TMJ sounds were reported in the present study. It may be attributed to emotional factors which increase parafunctional activity and/or muscle tension that can elicit tenderness or pain of the masticatory muscles correlated with TMJ sounds ${ }^{4,7}$. Similar to the results of the previous studies, an association between depression and muscle tenderness to palpation and reported facial pain were found in this study ${ }^{15,18,19,25}$. Vanderas ${ }^{13}$ and Alamoudi $^{7}$ studied on association between oral parafunctions, emotional status and signs and symptoms of TMDs. They evaluated emotional status as calm and nervous, pleasant and unpleasant. The authors reported significant association between emotional status and multiple signs and symptoms of TMDs. Vanderas ${ }^{13}$ observed a relationship between muscle tenderness, clicking and difficulty in opening and oral parafunctions in calm group. In another study, emotional stress was evaluated by means of urinary catecholamines in a 24-h urine sample and it was concluded that parafunctional and psychological factors might elevate the likeliness of the child developing signs and symptoms of TMDs ${ }^{6}$.

Within the limitation of the present study it was conclud- ed that oral parafunctions (nail biting, lip biting, especially bruxism), state anxiety and personality traits such as hysteria and depression were associated with signs and symptoms of TMDs in the adolescents who participated in this study. Oral parafunctions, personality characteristics and anxiety should be taken into consideration concurrently in treatment planning and a multidisciplinary approach involving dentists and psychologists is needed for a successful therapy.

\section{Conflict of interest}

None to be declared.

\section{References}

1. Gavish A, Halachmi M, Winocur E, Gazit E. Oral habits and their association with signs and symptoms of temporomandibular disorders in adolescent girls. J Oral Rehabil. 2000;27:22-32.

2. Winocur E, Gavish A, Finkelshtein T, Halachmi M, Gazit E. Oral habits among adolescent girls and their association with symptoms of temporomandibular disorders. J Oral Rehabil. 2001;28:624-629.

3. Okeson JP. Management of temporomandibular disorders and occlusion. 2nd ed., St Louis: Mosby; 1989. pp. 145-172.

4. Miyake R, Ohkubo R, Takehara J, Morita M. Oral parafunctions and association with symptoms of temporomandibular disorders in Japanese university students. $J$ Oral Rehabil. 2004;31:518-523.

5. Gilheaney Ó,Béchet S, Kerr P, Kenny C, Smith S, Kouider R, Kidd R, Walshe M. The prevalence of oral stage dysphagia in adults presenting with temporomandibular disorders: a systematic review and meta-analysis. Acta Odontol Scand. 2018;11:1-11.

6. Vanderas AP, Papagiannoulis L. Multifactorial analysis of the aetiology of craniomandibular dysfunction in children. Int J Paediatr Dent. 2002;12:336-346.

7. Alamoudi N. Correlation between oral parafunction and temporomandibular disorders and emotional status among Saudi children. J Clin Pediatr Dent. 2001;26:71-78. 8. Wieckiewicz M, Grychowska N, Wojciechowski K, Pelc A, Augustyniak M, Sleboda A, and et al. Prevalence and correlation between TMD based on RDC/TMD diagnoses, oral parafunctions and psychoemotional stress in Polish university students. Biomed Res Int. 2014;47:23-46. 9. Michelotti A, Cioffi I, Festa P, Scala G, Farella M. Oral parafunctions as risk factors for diagnostic TMD subgroups. J Oral Rehabil. 2010;37:157-162. 
10. Górecka M, Pihut M, Kulesa-Mrowiecka M.Analysis of pain and painless symptoms in temporomandibular joints dysfunction in adult patients. Folia Med Cracov. 2017;57:71-81.

11. Allen JD, Rivera-Morales WC, Zwemer JD. Occurrence of temporomandibular disorders symptoms in healthy young adults with and without evidence of bruxism. Cranio. 1990;8:312-318.

12. Kleinrok M, Mielnik-Hus J, Zysko-Wozniak D, Szkutnik J, Kaczmarek A, Doraczynska E, and et al. Investigations on prevalence and treatment of fingernail biting. Cranio. 1990;8:47-50.

13. Vanderas AP. Relationship between craniomandibular dysfunction and oral parafunctions in Caucasian children with and without unpleasant life events. J Oral Rehabil. 1995;22:289-294.

14. McCreary CP, Clark GT, Merril RL, Flack V, Oakley ME. Psychological distress and diagnostic subgroups of temporomandibular disorder patients. Pain. 1991;44:2934.

15. Yap AU, Tan KB, Chua EK, Tan HH. Depression and somatization in patients with temporomandibular disorders. J Prosthet Dent. 2002;88:479-484.

16. Laskin DM. Etiology of the pain dysfunction syndrome. J Am Dent Assoc. 1969;79:147-153.

17. Parker MW, Holmes EK, Terezhalmy GT. Personality characteristics of patients with temporomandibular disorders: Diagnostic and therapeutic implications. J Orofac Pain. 1993;7:337-344.

18. Karthik R, Hafila MIF, Saravanan C, , Priyadarsini P, Ashwath B. Assessing prevalence of temporomandibular disorders among university students: a questionnaire study. J Int Soc Prev Community Dent. 2017;7:24-29.

19. Velly AM, Gornitsky M, Philippe P. Contributing factors to chronic myofascial pain: a case-control study. Pain. 2003;104:491-499.

20. Kino K, Sugisaki M, Haketa T, Amemori Y, Ishikawa $\mathrm{T}$, Shibuya $\mathrm{T}$, and et al. The comparison between pains, difficulties in function, and associating factors of patients in subtypes of temporomandibular disorders. J Oral Rehabil. 2005;32:315-325.

21. Okeson JP. Orofacial pain: guidelines for assessment, diagnosis, and management. $3^{\text {rd }}$ ed., Chicago: Quintessence Publishing Co; 1996, p, 19-183.
22. Ceyhan B, Oral N. A Handbook of 'Minnesota Multhiphasic Personality Inventory'. Ankara: Bilimsel T⿰力 Press, 1998.

23. Öner N, Compte A. State-trait anxiety inventory. İstanbul: Boğaziçi University Press, 1985.

24. Silvia S, Cristian C, Markus J, Mauricio A. Cathal M, Angelo E, and et al. Socioeconomic status, non-communicable disease risk factors, and walking speed in older adults: multi-cohort population based study. BMJ. 2018;360;1-10.

25. Tommaso C, Andrea B, Gabriele R, Giovanni C, Andrea D. Sleep bruxism in adolescents: a systematic literature review of related risk factors. Eur J Orthod. 2016;38:18.

26. Johansson A, Haraldson T, Omars R, Kiliaridis S, Carlsson GE. A system assessing the severity and progression of occlusal wear. J Oral Rehabil. 1993;20:125-31. 27. Rugh JD, Harlan J. Nocturnal bruxism and temporomandibular disorders. Adv Neurol. 1988;49:329-41.

28. Fernandes G, Van Selms MK, Goncalves DA, Lobbezoo F,Camparis CM. Factors associated with temporomandibular disorders pain in adolescents. J Oral Rehabil. 2015;42:113-119.

29. Franco-Micheloni AL, Fernandes G, De Godoi GDA, Camparis CM. Temporomandibular disorders in a young adolescent Brazilian population: epidemiologic characterization and associated factors. J Oral Facial Pain Headache. 2015;29:242-249.

30. Murray GM, Phanachet I, Uchida S, Whittle T. The human lateral pterygoid muscle: a review of some experimental aspects and possible clinical relevance. Aust Dent J. 2004; 49:2-8.

31. Barbosa TS, Miyakoda LS, Pocztaruk RL, Rocha CP,Gaviao MB. Temporomandibular disorders and bruxism in child hood and adolescence: review of the literature. Int J Pediatr Otorbinolaryngol. 2008;72:299-314.

32. FrancoMicheloni AL, Fernandes G, Gonçalves DA, Camparis CM. Temporomandibular disorders among Brazilian adolescents: reliability and validity of a screening questionnaire. J Appl Oral Sci. 2014;22:314-22.

33. Gamsa A. The role of psychological factors in chronic pain. I. A half-century study.Review. Pain. 1994;57:5-15. 